\title{
The use of reported speech in children's narratives: a priming study
}

Article

Accepted Version

Serratrice, L., Hesketh, A. and Ashworth, R. (2015) The use of reported speech in children's narratives: a priming study. First Language, 35 (1). pp. 68-87. ISSN 0142-7237 doi: https://doi.org/10.1177/0142723715569552 Available at https://centaur.reading.ac.uk/65940/

It is advisable to refer to the publisher's version if you intend to cite from the work. See Guidance on citing.

To link to this article DOI: http://dx.doi.org/10.1177/0142723715569552

Publisher: SAGE Publications

All outputs in CentAUR are protected by Intellectual Property Rights law, including copyright law. Copyright and IPR is retained by the creators or other copyright holders. Terms and conditions for use of this material are defined in the End User Agreement.

\section{www.reading.ac.uk/centaur}

\section{CentAUR}

Central Archive at the University of Reading

Reading's research outputs online 
THE USE OF REPORTED SPEECH IN CHILDREN'S NARRATIVES: A PRIMING STUDY

The use of reported speech in children's narratives: A priming study Ludovica Serratrice, Anne Hesketh \& Rachel Ashworth

The University of Manchester

Corresponding author:

Ludovica Serratrice

The University of Manchester

School of Psychological Sciences

Ellen Wilkinson Building

Manchester M13 9PL

Tel: +44 (0) 1612757208

Email: serratrice@manchester.ac.uk 


\begin{abstract}
This study investigated the long-term effects of structural priming on children's use of indirect speech clauses in a narrative context. Forty-two monolingual English-speaking fiveyear-olds in two primary classrooms took part in a story re-telling task including reported speech. Testing took place in three individual sessions (pre-test, post-test1, post-test2) and the priming phase was conducted in 10 group priming sessions. During the priming phase the two classrooms were randomly allocated to one of two conditions where, over the course of two weeks, the children heard 10 different stories that included 30 tokens of either indirect or direct speech. In the pre-test session we collected measures of receptive vocabulary (BPVS-3) and expressive grammar (Formulated Sentences sub-test, CELF4-UK). There was a significant effect of input manipulation that was maintained for up to ten weeks after the training. Expressive grammatical skills were positively correlated with the likelihood of using indirect speech one week after the end of the language intervention.
\end{abstract}

\title{
Keywords:
}

Priming, complex syntax, indirect speech, narrative, subordination 


\section{Introduction}

One of the core issues in the literature on language development revolves around the relationship between child-directed input and children's language skills, and the extent to which what children hear is predictive of what they comprehend and produce. More specifically in an educational context, two of the fundamental questions are whether the language addressed to children at school affects the way they speak, and whether changes in classroom-based child-directed speech have a measureable long-lasting impact on specific aspects of children's language.

In the present study we investigated whether children's use of a complex syntactic construction in the context of a story-retelling task was affected by listening to stories containing a large number of tokens of the construction of interest. We specifically targeted the use of subordinate clauses to report speech indirectly (e.g. 'Max said that he was going to be late') as this construction taps into a set of sophisticated morpho-syntactic and discoursepragmatic skills required to produce spoken and written texts in a school context.

\section{The relationship between language in the classroom and syntactic development}

A vast and expanding body of research has shown that input matters, and that the quantity and the quality of the language that young children hear from their caregivers at home and at school affect their language comprehension and production in significant ways (Hoff, 2006; Huttenlocher, Vasilyeva, Cymerman, \& Levine, 2002). Correlational studies that have specifically addressed the relationship between teachers' input and children's syntactic skills have found a significant positive effect of the syntactic complexity in teachers' language as 
measured by multi-clause sentences, word types and word tokens (Gámez \& Levine, 2012; Huttenlocher et al., 2002).

A recent UK-based quasi-experimental study (Dockrell, Stuart, \& King, 2010), targeting children from disadvantaged backgrounds and English Language Learners (ELL), evaluated two language intervention programmes - Talking Time and story reading against a non-intervention group for gains in receptive and expressive lexical and syntactic skills in 142 4-year-old children. This piece of research is of particular relevance here as, similarly to the present study, it addressed a UK rather than a US population, and it included a focus on syntactic language gains as a result of the intervention, while the majority of intervention studies tend to focus exclusively on lexical gains.

The Talking Time intervention included three sets of activities with a focus on vocabulary, inference-making skills and narrative skills; children in the story reading intervention participated in interactive story reading sessions, while the children in the nonintervention group carried on with their standard pre-school curriculum. Both Talking Time and the story reading intervention significantly improved children's performance on a sentence repetition test, but only the Talking Time programme significantly affected children's receptive language and expressive vocabulary. Dockerell et al. (2010: 510) concluded that they "demonstrated that with regular evidence-based interactions significant improvements can be made". Although the effects of the Talking Time intervention were statistically significant, the authors also acknowledged that the teachers in the pre-school involved in that programme received specific training on a range of activities including modelling, recasting and highlighting contrasts between different words and different constructions, which the teachers in the story reading setting and the non-intervention setting did not receive. When the same level of teacher support was not provided, there was no evidence for 
children's language improvement. We interpret this as a caveat that the success of Talking Time did not solely depend on the type of activities that were targeted at the children, but equally on how they were implemented by their teachers. The targeted instructional focus on the use of language received by the teachers in the Talking Time intervention contributed to specific and fine-grained changes in teachers' linguistic behaviour that had cascading positive effects on children's own language use.

The role of stories and book reading intervention on children's language skills

Classroom-based interventions can take different forms, one in particular - shared book reading - has long been regarded as playing a significant role in fostering children's language and literacy skills. The findings for the positive effects of story reading on the acquisition of vocabulary are well established (see Marulis \& Neuman, 2010; Mol, Bus, de Jong, \& Smeets, 2008; Mol, Bus, \& de Jong, 2009, for recent meta-analyses), but its benefits on the acquisition of more complex syntactic skills are less clear. In a discussion of the US National Early Literacy Panel's report (NELP; 2008), Schickedanz and McGee (2010) focused on shared book reading, defined by the NELP as a variety of read-aloud methods and interactions with books whose main aim is to foster the development of vocabulary and grammar. Of particular interest here is their meta-analysis of five studies that included more complex expressive language measures in addition to receptive and expressive vocabulary measures (Lonigan, Anthony, Bloomfield, Dyer, \& Samwel, 1999; Morrow, O’Connor, \& Smith, 1990; Phillips, Norris, Mason, \& Kerr, 1990; Talley, Lancey, \& Lee, 1997; Zevenbergen, Whitehurst, \& Zevernbergen, 2003). The measure of complex expressive language was the same in the five studies - the Illinois Test of Psycholinguistic Abilities Verbal Expression Subscale (ITPA-VE; Kirk, McCarthy, \& Kirk, 1968), and four studies also 
included MLU as a proxy for grammatical complexity. The results were mixed as only three of the five studies reported a significant effect of the story reading intervention on the ITPA scores, and three out of four found a significant effect for MLU.

The relative paucity of studies explicitly targeting the relationship between exposure to stories and the acquisition of expressive syntactic skills, alongside some discrepant findings, make for a complex picture. As Cameron-Faulkner and Noble (2013: 270) recently pointed out, "methodological and theoretical issues may be playing a crucial role in this apparent lack of clarity". Their argument is that the input measures (e.g. frequency or style of shared book reading) used as predictors of children's grammatical abilities (e.g. standardized tests) are not sufficiently fine-grained to detect the presence of specific syntactic constructions that are the hallmark of more sophisticated linguistic competence (e.g. the use of passive constructions, different types of subordinate clauses). In their own study Cameron-Faulkner and Noble (2013) started investigating the specific nature of the language contained in pre-school children's books by analyzing the frequency of different types of syntactic constructions and comparing them to child-directed speech in naturalistic corpora. Their findings indicated that, compared to child-directed speech, the 20 books they analyzed contained a significantly higher proportion of subject-predicate constructions (e.g. 'He ate the cake', 'She's running', 'He put it there') and of complex structures including a main clause and a subordinate clause (e.g. 'I know that you love doing jigsaws', 'I thought that you had been here before').

This focus on a fine-grained and construction-based level of analysis can give us a better insight into which specific aspects of children's more sophisticated language skills benefit from the content of stories read to them. A fruitful line of inquiry in psycholinguistic 
THE USE OF REPORTED SPEECH IN CHILDREN'S NARRATIVES: A PRIMING STUDY

research has been dedicated to this very question and it is to the issue of syntactic priming and its implications for acquisition that we turn to next.

\section{Evidence for the effects of input manipulation: syntactic priming}

Research on adult language production has shown that speakers are significantly more likely to repeat a given construction if it is structurally similar to a previously encountered construction; i.e. they can be syntactically primed (see Pickering \& Ferreira, 2008 for a critical review). Syntactic alternations like the active/passive voice to describe a transitive event (e.g. 'Molly helped Laura'/'Laura was helped by Molly'), or the double object/prepositional object dative construction (e.g. 'Max gave Tess the book'/'Max gave the book to 'Tess') to describe a transfer event, have been shown to be affected by priming (Bock 1986; Pickering \& Branigan, 1998). Syntactic priming has theoretically been construed as either a form of transient activation of the structural information associated with the combinatorial nodes of a lexical entry at the lemma level (Pickering \& Branigan, 1998), or with changes in the mapping between meaning and structure over time resulting in a form of implicit learning (Chang, Dell, Bock, \& Griffin, 2000).

Lab-based investigations of priming in picture description tasks have shown that preschoolers too are sensitive to targeted input manipulation in syntactic priming experiments. Children have been successfully primed to produce: passives vs. actives (Bencini \& Valian, 2008; Brooks \& Tomasello, 1999; Huttenlocher, Vasilyeva, \& Shimpi, 2004; Messenger, Branigan, \& Mc Lean, 2011); double object vs. prepositional datives (Huttenlocher et al., 2004; Rowland, Chang, Ambridge, Pine, \& Lieven, 2012; Shimpi et al., 2007; Thothathiri \& Snedeker, 2008); adjectival phrases (e.g. 'The blue cat') vs. relative clauses (e.g. 'The cat that is blue') (Branigan, McLean, \& Jones, 2005), and pre-nominal vs. post-nominal constructions 
(e.g. 'The policeman's car vs. The car of the policeman') (Skarabela \& Serratrice, 2009). There is also some emerging evidence that these effects can last over time suggesting that priming can result in some form of longer term implicit learning (Kidd, 2012; Savage, Lieven, Theakston, \& Tomasello, 2003, 2006; Vasilyeva, Huttenlocher, \& Waterfall, 2006). Existing syntactic priming research is based on picture description tasks where the participants and the experimenter take turns at describing a series of pictures, a rather atypical communicative situation where there is little scope for purposeful linguistic interaction. One notable exception is the study by Vasilyeva, Huttenlocher, and Waterfall (2006) where concentrated exposure to passives was embedded in a series of narratives. In a much earlier study, Tomasello Brooks, and Stern (1998) had also embedded their passive primes in a larger discourse context, but crucially each prime was a stand-alone item, unconnected with the preceding and following items, and therefore there was no obvious sense in which the passive primes were part of a coherent narrative. In Vasilyeva et al.'s (2006) study four-year-old children were allocated either to the passive or to the active condition, and for two consecutive weeks they listened to 10 different stories - one a day that either contained a high concentration of passives or of actives. Aside from the use of narratives for the presentation of the primes, another innovative aspect of Vasilyeva et al.'s (2006) study was that they did not prime the children in individual sessions as is customary, but exposed them to the primed structure while they were listening to the stories as a group classroom-based activity. At the end of the training phase there was a significant effect of input manipulation; children in the passive condition performed significantly better both in the comprehension and production of passives than the children in the active condition. To our knowledge, this is the first study to bridge the gap between lab-based evidence about syntactic priming and the classroom environment. 
THE USE OF REPORTED SPEECH IN CHILDREN'S NARRATIVES: A PRIMING STUDY

The current study was motivated by a similar concern for ecological validity; the rationale was to assess the effects of input manipulation in a language training task that was as similar as possible to the kind of language and literacy activities that are already embedded in the school curriculum; i.e. shared book reading and story telling. At the same time our intervention went beyond everyday practice as we deliberately manipulated the content of the stories so that they specifically contained a high number of syntactic constructions of interest. Narratives are an important part of children's communicative competence (Berman \& Slobin, 1994; Cameron, Hunt, \& Linton, 1988; Gamanossi \& Pinto, 2014; Geva \& Olson, 1983; McCabe \& Peterson, 1991) and feature prominently in their school-based language and literacy activities. Showing that priming works in an open-ended task like story-telling has the obvious practical advantage of allowing targeted input manipulation in the context of shared reading activities in a classroom-friendly environment.

\section{Does priming work for everyone? Individual differences in susceptibility to priming}

What is often overlooked in the reporting of the results of priming studies is the extent of individual variation within the sample. For example Bencini \& Valian (2008) reported a significant effect of priming condition (passive vs. active) in 3-year-olds' production of the passive, even though between $20 \%$ and $60 \%$ of children, according to whether a lax or strict coding was used, did not produce any passive constructions. Messenger, Branigan, McLean, and Sorace $(2008,2009)$ also reported large standard deviation measures in their studies of passive priming, and Messenger, Branigan, and McLean (2011) found that only 8 out of the 16 children in their experiment produced at least one full passive.

Kidd (2012) was the first study that specifically addressed individual child variation in susceptibility to priming by exploring the relationship with verbal and non-verbal skills. In 
the present study we also explored the relationship between independently measured verbal skills (receptive vocabulary and expressive grammar) and the likelihood of priming. Our rationale for doing so was three-fold. Firstly, it is critical to understand variation per se as a hallmark of language development, a fact that is too often ignored in the literature on priming where sweeping generalizations are made about children's mental representations at a given age (e.g. Bencini \& Valian, 2008: 109). Secondly, if individual variation exists among children in the likelihood and magnitude of priming, then we need to know more about the determinants of this variation. Finally, if syntactic priming is indeed a form of implicit learning, a better understanding of how priming works in children will give us an insight into what facilitates language development in its own right, and what works for different children at different stages; this information is going to be of interest to those who have more specific involvement with intervention and pedagogy.

\section{Targeting indirect speech clauses}

One of the criticisms of previous education and literacy research on the role of story reading and the development of complex language leveled by Cameron-Faulkner and Noble (2013) was the lack of a finer degree of granularity in investigating children's syntactic skills at the level of individual constructions. The measures that are typically used in this line of research (e.g. how frequently children are read to; teachers' or parents' reading style) are rather coarse indicators of the kind of input that may affect children's uptake of particular aspects of complex syntax, e.g. subordination. In line with this approach we decided to focus on a type of subordinate clause that is key to story telling: the use of indirect speech subordinate clauses. 
THE USE OF REPORTED SPEECH IN CHILDREN'S NARRATIVES: A PRIMING STUDY

Talk about speech is an important aspect of a speaker's communicative skills. The reporting of speech events is particularly interesting developmentally because it requires the integration of sophisticated morphological, grammatical, and discourse-pragmatic skills. In English a speech event can be reported as direct speech, as in (1) or indirect speech as in (2):

(1) Laura said: "I'm going to get a taxi to go to your house".

(2) Laura said (that) she was going to get a taxi to come to my house.

In (1) the speaker reproduces the original quote verbatim by prefacing it with a main clause including the verb said. In (2) the main clause introduces a subordinate clause optionally starting with the complementizer that. In discourse-pragmatic terms, the choice of indirect speech requires the speaker to appreciate a shift of perspective from the speaker of the original utterance in (1) to the speaker reporting a third party's utterance in (2). In lexical and morphological terms this pragmatic awareness must translate into the choice of relevant pronouns (e.g. 'she' vs. 'I') and verb forms (e.g. 'she was' vs. 'I'm'). In addition to differences in lexical and morpho-syntactic expression, there is variation between direct and indirect speech with respect to communicative functions. According to Clark and Gerrig's (1990) demonstration theory a speaker's choice in reported speech is strongly determined by the intended function of the retelling. Direct speech is more likely to be used if the speaker's purpose is to entertain the speaker, while indirect speech is more closely associated with a purely informative function in addressing a naïve listener (Wade \& Clark, 1993).

The discourse-pragmatic, lexical and morpho-syntactic competence required by the use of indirect speech clauses is not trivial, and there is evidence that, developmentally, indirect speech emerges later than direct speech (Ely \& McCabe, 1993; Hickmann, 1993; 
THE USE OF REPORTED SPEECH IN CHILDREN'S NARRATIVES: A PRIMING STUDY

Goodell \& Sachs, 1992; Nordqvist, 1998, 2001; Özyürek, 1996).

\section{The present study}

This study investigated whether English-speaking 5-year-old children could be primed to use indirect speech in a story-retelling task. Two year-1 primary school classes (children between the ages of 5 and 6) were randomly allocated to one of two priming conditions: the indirect speech condition (IS) or the direct speech condition (DS). Over the course of two school weeks each group of children listened to one story a day that either contained 20 tokens of indirect speech primes (IS condition) or 20 tokens of direct speech primes (DS condition). While the priming phase was delivered collectively to each of the two groups, the children were individually assessed in a pre-test phase and in two post-tests, the first one week after the end of the priming phase and the second 10 weeks after.

We selected children between the ages of 5 and 6 because they are at the stage immediately preceding Key Stage 2 (7-11 years of age) where the use of subordination is explicitly taught in the English National Curriculum

(https://www.gov.uk/government/uploads/system/uploads/attachment_data/file/335190 /English_Appendix_2_-_Vocabulary_grammar_and_punctuation.pdf). We decided to set up a context in which the experimenter had not had shared access to the story prior to the re-telling as there is evidence that indirect discourse is more likely to be used to inform a naïve listener (Geva \& Olson, 1983; Wade \& Clark, 1993). The use of a story was motivated by the desire to embed the targeted syntactic construction in a meaningful discourse that may add to children's uptake in the context of priming (see Kidd, 2012 for a similar suggestion). The specific research questions and predictions were the following: 
1) Is a short-term daily exposure to stories containing a high concentration of indirect speech clauses effective in promoting children's use of indirect speech in a story-retelling task?

On the basis of previous findings using input manipulation in a narrative context over a two-week period (Vasilyeva et al., 2006), we predicted that children exposed to stories containing a high concentration of indirect speech would produce more indirect speech clauses in a story-retelling task than children exposed to the same stories containing a high proportion of direct speech clauses.

2) Are the effects of targeted exposure to indirect speech maintained over time?

Children were tested one week and ten weeks after the end of the two-week training period; we expected that, if the effects of language training are maintained, the proportion of indirect subordinate clauses to report speech should be maintained at time 2 .

3) Is there a positive correlation between children's receptive vocabulary skills and/or expressive grammatical skills and the likelihood of producing indirect speech clauses after training?

Preliminary evidence indicates that receptive lexical and syntactic skills are positively correlated with the magnitude of priming effects (Kidd, 2012; but see Messenger et al., 2011 for a non-significant effect of BPVS scores on priming). The prediction for the present study was that performance on the British Picture Vocabulary Scale, (BPVS-3; Dunn, Dunn, Styles, \& Sewell, 2009) and the Formulated Sentences sub-test of the Clinical Evaluation of Language Fundamentals (CELF4-UK; Semel, Wiig, \& Secord, 2006) would be significantly higher for those children in the indirect speech condition that were successfully primed to 
THE USE OF REPORTED SPEECH IN CHILDREN'S NARRATIVES: A PRIMING STUDY

use indirect speech clauses after training.

\section{Methods}

Participants

Indirect Speech (IS) Direct Speech (DS)

The study received ethical approval by the authors' University Research Ethics Committee. Forty-two English-speaking children were recruited from a primary school in the North of England, UK (24 girls). According to teachers' reports all the children included in the study had English as their only language. The Office for National Statistics ranked the 32,482 neighbourhoods in England on a range of deprivation topics with the most deprived neighbourhood having a rank of 1; in 2010 the school recruited in this study was in a postcode area with a rank of 18031 . The children were in two classes that were randomly assigned to one of two priming conditions: Indirect Speech condition (IS, $\mathrm{N}=21$ ) or Direct Speech condition (DS, $\mathrm{N}=21)$.

Table 1 reports the descriptive statistics for the participants in the two priming conditions. There were no significant differences between the two groups with respect to age in months, $t(40)=.60, p=.55$, receptive vocabulary as measured by standard scores on the BPVS-3, $t(40)=.86, p=.39$, or expressive grammatical abilities as measured by the scaled scores on the Formulated Sentences sub-test of the CELF4-UK,t(40) $=1.46, p=.15)$. 
THE USE OF REPORTED SPEECH IN CHILDREN'S NARRATIVES: A PRIMING STUDY

\begin{tabular}{cccccc}
\hline Age in & BPVS & CELF & Age in & BPVS & CELF \\
months & & months & & $(\mathrm{FF})$ \\
$70.10(3.68)$ & $92.38(7.65)$ & 8.62 & 69.43 & 90.62 & 7.10 \\
& & $(4.04)$ & $(3.50)$ & $(5.38)$ & $(2.50)$ \\
\hline
\end{tabular}

Table 1.

Descriptive statistics for the participants in the two priming conditions including Means and (Standard Deviations). Age in months, BPVS-3 standard scores Formulated Sentences subtest CELF4-UK scaled scores

For both groups the mean standard scores for receptive vocabulary and expressive grammar were within 1 SD below the mean indicating that, although they were in the typically developing range, these children did not have particularly advanced language skills as a whole. We deliberately targeted a school in a moderately socially deprived area, these relatively low language scores are therefore not surprising and very much in line with the typical profile of the school's intake.

\section{Materials}

The training materials consisted of thirteen different stories loosely based on children's books or traditional folk tales; they were compiled into PowerPoint presentations with ClipArt pictures or into videos using toy figurines and simple props. The visual materials were accompanied by a digital recording of the story narrated by a speaker reading from a script. The stories were on average 90 clauses long and contained 20 tokens each of reported speech. Three stories were used for the three testing sessions; the remaining 10 were used in the training. Each of the 10 stories used in the priming phase had two versions: in the IS 
condition version the reported speech was realized by indirect speech clauses, in the DS condition version we used the direct speech counterpart for the same speech events. Aside from the IS/DS manipulation, the stories were identical in the two versions.

With specific reference to the two stories used in the two post-tests, in terms of the main verbs used, in post-test 1 there were four different verb types: said $(\mathrm{N}=7)$, asked $(\mathrm{N}=$ 3), replied $(\mathrm{N}=2)$ and demanded $(\mathrm{N}=2)$. Out of 20 indirect speech contexts 14 subordinates were introduced by one of these verbs of saying and 6 were coordinated to the first subordinate (e.g. 'The little girl replied that she was on her way home and that she had to tell her Mum a secret'). The pattern was very similar in post-test 2 with five different main verb types: said $(\mathrm{N}=8)$, asked $(\mathrm{N}=2)$, replied $(\mathrm{N}=1)$, sobbed $(\mathrm{N}=1)$, and admitted $(\mathrm{N}=1) ; 13$ subordinates were introduced by one of these verbs of saying and 7 IS clauses coordinated to the first IS subordinate. Both stories had an episodic structure where the main character was involved in 4 different scenes. The only difference between the stories at post-test1 and post-test 2 is that at post-test 1 the protagonist met three different characters with whom she engaged in a very similar dialogue. In the story at post-test2, in contrast, the little girl complained about a sore finger to four characters and to each of them she gave a different explanation.

\section{Design}

The study employed a between-subjects repeated measures design. The between-subjects variable was priming condition (IS, DS), the within-subjects variable was time (post-test 1 , post-test 2). During the two-week priming phase the children in the IS condition were exposed to stories containing only examples of indirect speech and the children in the DS

condition only heard stories including tokens of direct speech. During the two post-tests all 
children were primed with stories containing only indirect speech; all children also took part in an initial pre-test session where they were exposed to a story that only contained direct speech and they were administered standardized tests of receptive vocabulary and expressive syntax.

\section{Procedure}

Before the start of the training phase the children were individually assessed by the third author for levels of receptive vocabulary (BPVS-3) and expressive grammaticsl abilities (Formulated Sentences sub-test of the CELF-4 UK).

Children were seen individually by a trained researcher on three separate occasions: before the start of the priming phase (pre-test), one week after the end of priming (posttest1), and ten weeks after the end of priming (post-test2). The third author assessed children in the pre-test session and delivered the training; a different researcher, blind to the children's training condition, conducted the post-tests.

Language measures were collected during the pre-test session before the story retelling task. Children's responses in the BPVS-3 were scored by the researcher during the test; those in the CELF-4 UK were digitally recorded, transcribed and scored later by the same researcher. Approximately $20 \%$ of answers in the Formulated Sentences sub-test were independently coded by the second author, a qualified speech and language therapist.

Reliability was high between the two raters $(k=.90)$; any disagreements were resolved between the two coders.

During the story re-telling sessions (pre-test, post-test1, post-test2) the child first sat at a table where a 15-inch laptop was set up, the researcher started a video with the audionarration turned on and left the child to watch by herself asking her to pay attention to the 
story as she would later have to re-tell it. While the child was watching the video, the experimenter sat in a far corner of the room attending to her paperwork. When the child had finished watching the video, the experimenter returned to the child's table and started the video again, this time with the sound off, and encouraged the child to tell her the story in her own words. The idea was to get the child to act as an informant for the benefit of a naïve listener.

In the pre-test session the story contained only examples of direct speech; this was because we wanted to have some initial indication of whether children would ever spontaneously choose to use indirect subordinate clauses to report speech in the story retelling.

The priming was delivered to the two groups of children collectively by the experimenter who tested them in the pre-test session. Each group of children sat in their classroom, and watched the videos/PowerPoint presentations projected on a big screen while the researcher read the story from a script. The children were told that they were going to watch a story, and that they had to pay attention to help Fred the frog understand what was going on. Fred was introduced as a curious toy frog with a tendency to fall asleep and then suddenly wake up wanting to know who had said what in the story. Fred asked questions for 10 of the 20 reported speech events (e.g. Fred: 'Children, what did the witch say?') and he also asked a number of other factual questions to encourage the children's participation (e.g. Fred: 'Children, what colour was the witch's hat?'). To leave this task as natural as possible, and to simulate a typical classroom activity, the experimenter left it to the children's initiative to answer the questions. After the children's replies the experimenter modeled the answer herself and used either indirect or direct speech depending on the priming condition. In each condition the children were therefore exposed to 30 instances of 
either direct or indirect speech per story, for a total of 300 instances over 10 days in two consecutive school weeks.

In post-test 1 and post-test 2 a different researcher followed the same protocol as in the pre-test session but with different stories. The post-test stories contained only examples of indirect speech as we wanted to measure whether children could be primed to use indirect speech in their retelling and, more importantly, whether the likelihood that they would do so at post-test was significantly determined by prior exposure to indirect speech in the twoweek priming phase. During the re-telling of the stories the experimenter gave minimal prompts (e.g. 'That's right! Really?'), and never cued the children explicitly in the use of reported speech. Children's narratives were digitally recorded for later transcription and for the coding of reported speech.

\section{Transcription and coding}

The children's narratives in the pre-test, post-test 1 and post-test 2 sessions $(N=126)$ were transcribed by two trained English native speakers using the CHAT system as described in the CHILDES manual (MacWhinney, 2000).

All instances of reported speech were coded by the third author as direct speech or indirect speech following a set of morphological and syntactic criteria based on existing literature (e.g. Nordqvist, 2001) and illustrated earlier in the text in examples (1) and (2). We relied on the use of pronouns, tensed verb forms andpauses as diagnostic tools, and on the complementizer that, whenever it was overtly realized. In the absence of a complementizer that unambiguously identified a subordinate as an instance of indirect speech, a clause was classed as direct speech if there was a detectable prosodic boundary between the verb of saying and the beginning of the next clause. The use of voices was also taken as a clear 
indication for direct speech; children often put on a different voice when quoting directly one of the characters in the stories (O’Neill \& Holmes, 2002). All the coded utterances were checked against the original recordings by the first author $(\mathrm{k}=.80)$; any disagreements were resolved before inclusion in the final count.

\section{Results}

Table 2 reports the descriptive statistics for the proportion of IS clauses over the total number of IS and DS clauses, for the pre-test and the two post-tests for the two priming conditions.

\section{Table 2.}

Proportions of IS clauses over total number of IS+DS clauses as a function of test phase and priming condition

\begin{tabular}{lcccccc}
\hline & \multicolumn{3}{l}{ IS condition } & & & \\
& Mean & SD & Range & Mean & SD & Range \\
\hline Pre-test & .32 & .42 & $0-1$ & .12 & .23 & $0-1$ \\
\hline Post-test 1 & .38 & .40 & $0-1$ & .06 & .23 & $0-1$ \\
\hline Post-test 2 & .80 & .31 & $0-1$ & .54 & .33 & $0-1$ \\
\hline
\end{tabular}


This measure is an indicator of the children's willingness to use the IS construction over the DS construction when they chose to report speech; i.e. it is a measure of children's shifting preference for the indirect speech construction.

Independent samples $t$-tests confirmed that the groups did not differ significantly at pre-test in the proportion of IS clauses over the total number of IS and DS clauses, $t(40)=$ $1.87, p=.06$.

To test for significant effects of priming condition over time, two mixed ANCOVAs were conducted with priming condition (IS condition, DS condition) as a between-subjects variable, time (post-test1, post-test2) as a within-subjects variable, and proportion of IS/IS+DS at pre-test as a covariate. The dependent measure was the arcsine transformed proportion of IS clauses over the total number of IS and DS clauses.

The effect of training condition was significant, $F(1,39)=8.79, p<.01$, partial ${ }^{2}=$ .18 , confirming that children in the IS condition used a significantly greater proportion of IS clauses to report speech than children in the DS condition. The effect of time was also highly significant, $F(1,39)=17.02, p<.001$, partial ${ }^{2}=.30$, showing that children produced a greater proportion of IS clauses at post-test 2 than at post-test 1 . The effect of the covariate was not significant, $F(1,39)=1.44, p=.23$, partial ${ }^{2}=.03$; this suggests that the higher proportion of IS/IS+DS clauses for the children in the IS condition at pretest did not affect the results of the priming. The interaction between time and condition was not significant, $F(1,39)=.55, p=.46$, partial ${ }^{2}=.01$; regardless of condition all children produced a greater proportion of IS clauses at post-test2. Moreover, not only was the 
THE USE OF REPORTED SPEECH IN CHILDREN'S NARRATIVES: A PRIMING STUDY

proportion of IS clauses higher at post-test2 than at post-test1, but so was the number of children who produced at least one IS clause in their narrative. At post-test1 16 out of 42 children (38\%) produced at least one IS clause (14 in the IS condition and 2 in the DS condition), while the number at post-test 2 went up to 38 out 42 (90\%) (19 children in each condition).

\section{The relationship between priming and language abilities}

The main effect of priming condition was significant, those children who were primed with IS clauses in the training stories did produce a larger proportion of IS clauses during the post-test phases than the children who had been primed with DS clauses in the training phase. Nevertheless, closer inspection of the individual data revealed that 7 out of the 21 children in the IS condition did not respond to the priming inasmuch as they did not produce any tokens of IS at post-test 1 . Because at post-test 2 only 2 out of 21 children in the IS condition did not respond to the priming, the analyses in the following section will explore in more depth the potential source of the variation only at post-test 1 .

One of the hypotheses tested in this study was that independently measured language abilities would predict children's propensity to be primed and therefore account for the expected and observed individual differences. Following Kidd (2012) the children in the IS condition who responded to the priming, and produced at least one token of IS at posttest1, were included in the 'primed' group $(\mathrm{N}=14)$, those who did not were in the 'not primed' group $(\mathrm{N}=7)$. To confirm whether children who responded to the priming did indeed have significantly higher lexical and grammatical abilities we carried out two independent t-tests between the 'primed' and the 'not primed' groups on BPVS standard scores and Formulated Sentences sub-test standard scores. We also included a third t-test on 
the proportion of IS clauses at pre-test to ascertain whether susceptibility to priming was in any way related to a pre-existing propensity to use the construction, rather than to independently measured language skills (a Bonferroni correction was applied for each of the tests, alpha $=.05 / 3=0.016)$. The children who responded to the priming had significantly higher expressive grammatical skills $(M=10.29, S D=2.73)$ than those who $\operatorname{did} \operatorname{not}(M=$ $5.29, S D=4.34), t(19)=3.24, p<.001$. No differences existed in terms of receptive lexical skills between the 'primed' $(M=93.43, S D=7.16)$ and the 'not primed' children $(M=$ $90.29, S D=8.75), t(19)=.88, p=.38$; there were equally no differences for the proportion of IS clauses over DS+IS clauses at pre-test between the 'primed' $(M=.36, S D=.56)$ and the 'not primed' children $(M=.67, S D=.83), t(19)=1.0, p=.32$.

Interestingly, the expressive grammatical skills for the children who did not respond to the priming at post-test 1 were more than 1 SD below the mean (5.29), an indication that these children had particularly poor grammatical abilities, in contrast to their receptive lexical skills which were within 1 SD of the mean (90.29). For the children who did benefit from the training in the IS condition the mean standard scores for the BPVS were within 1 SD deviation below the mean (93.43), while the Formulated Sentences standard score was just above the mean value of 10 (10.29). Although priming condition was a significant determinant of IS use at post-test 1, these additional analyses show that the two-week training period had benefitted only those children who already had more sophisticated expressive syntactic skills on entry to the study.

\section{Discussion}

The aim of the present study was to investigate the effectiveness of targeted input 
THE USE OF REPORTED SPEECH IN CHILDREN'S NARRATIVES: A PRIMING STUDY

manipulation during story re-telling, a communicative situation that is typical of children's everyday language use in and out of the classroom. Children who, in the training phase, were primed with stories containing indirect speech were more likely to use indirect speech in their own story re-telling in the post-test assessments than children who had been primed with stories including direct speech. Over time all children produced more indirect speech clauses regardless of training condition. Interestingly, those children who did respond to the priming were those who had more advanced grammatical skills as measured by a standardized test of sentence formulation.

\section{Priming complex constructions in narratives: the effects of input manipulation in a classroom context}

A substantial number of correlational studies have shown that input to children matters and that the quantity and the quality of caregivers' speech are positively correlated with the development of vocabulary and syntactic skills in the preschool and early school years (Hoff, 2006; Huttenlocher, Vasilyeva, Cymerman, \& Levine, 2002). In a parallel line of research, lab-based experimental studies on the effects of input manipulation have shown that children's use of a range of syntactic constructions can be successfully primed in the context of picture-description tasks (Bencini \& Valian, 2008; Branigan, McLean, \& Jones, 2005; Brooks \& Tomasello, 1999; Huttenlocher, Vasilyeva, \& Shimpi, 2004; Kidd, 2012; Messenger, Branigan, \& Mc Lean, 2011; Rowland, Chang, Ambridge, Pine, \& Lieven, 2012; Shimpi et al., 2007; Thothathiri \& Snedeker, 2008). While the granularity, i.e. the level of detail, and the timescale of these two types of research are rather different, together they provide evidence for the complex role of input in language development at a global and at a more local construction-based level.

The present study's main aim was to embed the use of the priming methodology in 
an ecologically valid narrative context during classroom literacy activities. The rationale was to take priming out of the lab and into the classroom, and test whether the significant effects of input manipulation that have so far been observed in the context of picture-description tasks could be replicated and extended to a more meaningful communicative task like storyretelling.

Our findings show that children's use of indirect subordinate clauses to report speech changed after targeted and concentrated language training over a two-week period. During the pre-test task there was very little evidence for spontaneous use of indirect speech; this finding was unsurprising and was consistent with previous evidence in the literature (Ely \& McCabe, 1993; Hickmann, 1993; Goodell \& Sachs, 1992; Nordqvist, 1998, 2001; Özyürek, 1996). And yet the ability to use indirect speech is necessary for the construction of sophisticated spoken and written texts; encouraging its use is therefore desirable from an educational point of view as it simultaneously taps into a range of advanced morphological, syntactic and discourse-pragmatic skills.

The allocation of the two groups to different training conditions, only one of which targeted the use of the more infrequent indirect speech construction, was consistent with the design of previous experimental priming research with child participants (but see Rowland et al., 2012 for a within-subjects priming experiment with children). However, unlike in most previous studies, the priming phase was delivered to the children as a group rather than individually, and the children were exposed to the two-week daily training as part of their routine school language and literacy activities. The results of the two post-tests showed that the children in the IS training condition increased the proportion of indirect subordinate clauses to report speech in their individual narratives; we also observed a cumulative effect over time whereby the proportion of IS clauses over the total number of utterances and over 
THE USE OF REPORTED SPEECH IN CHILDREN'S NARRATIVES: A PRIMING STUDY

the total number of IS and DS clauses increased from post-test1 to post-test2.

\section{The effect of input manipulation over time}

The proportional increase of the use of indirect speech clauses over time was observed both for the children in the IS condition and those in the DS condition, although the lack of priming $\mathrm{x}$ phase interaction indicates that the difference between the two groups was maintained at post-test 2 . We think that two different factors are responsible for the overall increase of indirect speech between post-test1 and post-test2: the differences in the episodic structure of the two narratives, and the effects of cumulative priming. .

With respect to the specific features of the story at post-test2, we can only speculate that its episodic structure may have been particularly conducive to the uptake of the targeted construction, given that the two post-test stories were virtually identical in the number of main verbs used to introduce indirect speech subordinates, and in the relative frequency of indirect speech appearing in coordinate clauses. At post-test 2 indirect speech was framed in a series of episodes where the protagonist gave slightly different explanations for the same incident. This feature of the story may have highlighted the verbal explanations and contributed to signposting the indirect speech clauses.

Another relevant issue regarding the increase of indirect speech clauses over time is the notion of cumulative priming. Unlike the majority of lab-based priming studies in the child literature (but see Kidd 2012; Savage et al. 2006 for two exceptions), the present study tested for the effects of input manipulation over a period of weeks, specifically one and ten weeks after the two-week language training. We found a significant positive effect of phase with a higher proportion of indirect speech being produced at post-test2; this long-term persistence of the effects of input manipulation is consistent with a view of priming as a 
form of implicit learning (Chang, Dell, \& Bock, 2006; Kaschak, 2007). From the point of view of development the argument has been made that structural repetition strengthens the entrenchment of syntactic representations and over time it leads to their acquisition (Brooks \& Tomasello, 1999; Savage et al., 2003).

Of particular relevance to the current experiment is a study by Kaschak, Kutta, and Schatschneider (2011) where participants were successfully primed to produce either a double object (DO) ditransitive construction (e.g. 'The swimmer handed the diver the towel'), or a prepositional object (PO) ditransitive construction (e.g. 'The swimmer handed the towel to the diver') a week after having been exposed to instances of PO or DO constructions in the priming phase. Kashack et al.'s prediction was that replicating the same context in the test that the participants had experienced during the priming phase one week earlier would contribute to getting them to make "language production choices to reflect the experience in the first session of the experiment." (Kashack et al., 2011: 383). In essence the claim was that language producers are sensitive to context of language use and that the recreation of certain contextual conditions would facilitate the production of those constructions that were found in the original context. Kaschak et al. (2011) proposed that syntactic choices can be equally triggered by the general context of language use, for example by the re-creation of the experimental context as an integral part of classroom activity. In the current study that is exactly what we did in our two test sessions where a story telling context very similar to the one that children had originally experienced during the training phase was re-created at a later date in the post-tests. The cumulative effect of priming over time is consistent with Kaschak et al.'s proposal; these findings contribute to expanding current understanding of what facilitates language producers' syntactic choices by taking a broader look at how input manipulation can be effectively re-created in a classroom context. 


\section{Individual differences in the likelibood of priming}

The final aim of this study was to explore the relationship between individual variation in the effects of language training and in language skills. Even in the presence of significant mean group differences showing an effect of priming there are often differences in the extent to which individual children respond to priming. These individual differences are either not often reported, or not investigated in any systematic way. A recent paper by Kidd (2012) is one notable exception as it explored independent linguistic and non-verbal determinants of syntactic priming in children. In Kidd's study children's tendency to be primed was significantly predicted only by their non-verbal ability, after controlling for the contribution of receptive vocabulary and grammatical skills, and age, but the magnitude of the priming effect was predicted by vocabulary and grammatical skills. These findings point to a role of linguistic and non-linguistic abilities to explain individual differences in the likelihood of priming and the degree to which children respond to input manipulation.

In the current study we also included a measure of receptive vocabulary (BPVS-3) but we measured children's expressive (rather than receptive) grammatical skills as we expected that they would be more indicative of performance on a complex syntactic production task. The only significant difference that we found between those children in the IS condition who responded to the priming and produced at least one token of IS at post-

test1, and those who did not, was in the scaled scores for the Formulated Sentences sub-test, i.e. our expressive grammar measure. Our experimental task tapped into the ability to use subordination by crossing clausal boundaries, and, as such, a test of single word knowledge like the BPVS-3 is unlikely to reflect the kind of knowledge required to succeed in such a task. In essence, a large vocabulary is necessary to become a competent speaker but it is not 
sufficient; syntactic abilities must also be developed to a certain level before children can benefit from exposure to complex constructions.

\section{Limitations of the present study}

This study represents a first step in embedding priming in the context of everyday classroom language and literacy activities with a view to extending previous findings of lab-based experimental research to a communicatively meaningful task like story re-telling. The children who participated in the shared reading of stories that included indirect speech did make use of subordinate clauses for reported speech more often after the training phase. There may be other additional reasons why the children in the IS condition benefitted from the training, potentially because of differences related to teacher style, quantity and quality of input throughout the rest of the school day. We did not control for these extra factors and therefore we acknowledge that we cannot rule out additional, but not mutually exclusive, explanations for our findings. In a set-up not unlike the present one, Dockrell et al. (2010: 510) make similar allowances for the positive effects of the Talking Time intervention programme and the potential confounds of teacher style and teacher training. In future research it would be desirable to recruit larger samples of children and use more than one teacher/classroom in each of the training conditions to control for this potentially confounding variable.

Another limitation of this study is the absence of free speech samples to evaluate the extent to which the use of indirect speech subordinates would translate to their actual language use outside of a testing situation. It would therefore be desirable for future studies to include additional measures of spontaneous language use, although this was beyond the scope of the current experimental design. 
THE USE OF REPORTED SPEECH IN CHILDREN'S NARRATIVES: A PRIMING STUDY

A final issue is the lack of a control group where children could have followed the same training protocol but with stories that did not include any instances of either direct or indirect speech. Although we did find a significant effect or priming, in the absence of an additional control group we cannot exclude that children would have increased their proportional use of indirect speech clauses anyway as part of their overall linguistic development.

\section{Conclusions}

The findings of this study add to the expanding literature on the role of input and input manipulation in children's developing syntactic skills in three main ways. Firstly, we have taken a new step in the investigation of the effects of language training in the context of children's everyday school language use; this has implications for furthering our understanding of how contextual factors affect linguistic experience. In turn this also has more practical pedagogical consequences as our findings have shown that embedding a complex syntactic construction in classroom-based activities has positive consequences on children's uptake and use. This has implications both for the design and use of literacy materials targeting specific aspects of syntax, and also for teachers' own use of constructions of interest in the speech they address to children in the classroom. After targeted exposure over a short period children's own use of complex constructions like indirect speech clauses changed over time. The next logical step would be the semi-naturalistic manipulation of teachers' own use of given constructions and assessment of the extent to which this input is taken up by children. Manipulation could also be extended to a wider range of complex subordinate clauses that children have to master to become competent and sophisticated language users (e.g. relative clauses, hypotheticals). Our findings also have implications for 
targeting the appropriate level of granularity when we consider the relationship between classroom-based input and children's use of complex grammar. Focusing on specific aspects of grammar by embedding selected syntactic constructions of interest in texts for shared reading/narrative activities is likely to prime their use in children's own production in predictable and targeted ways. Such a fine-grained approach at the level of individual constructions (e.g. relative clauses, complement clauses, passives) to create and/or adapt relevant texts is likely to prime children to re-use these very same constructions in their own speech. Changes in linguistic behaviour would therefore affect the sophistication and complexity of children's expressive syntactic skills in very concrete ways.

Secondly, we have reported long-term use of the targeted construction over the course of up to ten weeks after the end of the training phase. The limitations of the present study prevent us from drawing firm conclusions on the level of entrenchment and productivity of IS speech in the children who were successfully primed as we used a very open-ended task and we did not measure additional variables that could at least partly explain our results (e.g. teacher style, amount of talk). These findings are nevertheless consistent with a view of structural priming as a form of implicit learning. Something changed in the linguistic behaviour of our participants as a result of the training, and these changes were not limited to the confines of one experimental session but persisted over a matter of weeks.

Thirdly, we have started to explore individual differences in sensitivity to priming and reported a significant effect for expressive grammatical skills. Future work will need to explore in more detail both the longer term effects of input manipulation, and the nature of the linguistic and cognitive correlates of structural priming in children to gain a better understanding of the mechanisms promoting the development of complex syntactic 
THE USE OF REPORTED SPEECH IN CHILDREN'S NARRATIVES: A PRIMING STUDY

knowledge.

\section{References}

Bencini, G., \& Valian, V. (2008). Abstract sentence representations in 3-year-olds:

Evidence from language production and comprehension. Journal of Memory and Language, 59, 97-113.

Berman, R. A., \& Slobin, D. I. (1994). Relating events in narratives. A crosslinguistic developmental study. Mahwah, NJ: Lawrence Erlbaum.

Bock, K. (1986). Syntactic persistence in language production. Cognitive Psychology, 18, 355387.

Bornstein, M. H., Haynes, M. O., \& Painter, K. M. (1998). Sources of child vocabulary competence: A multivariate model. Journal of Child Language, 25, 367-393.

Branigan, H. P., McLean, J. F., \& Jones, M. W. (2005). A blue cat or a cat that is blue? Evidence for abstract syntax in young children's noun phrases. In A. Brugos MR Clark-Cotton S. Ha (Eds.), The Proceedings of the 29th Annual Boston University Conference on Language Development (pp. 109-121).

Branigan, H., Pickering, M., Stewart, A., \& Mclean, J. (2000). Syntactic priming in spoken production: Linguistic and temporal interference. Memory and Cognition, 28, $1297-1302$.

Branigan, H., Pickering, M., \& McLean, J. (2005). Priming prepositional-phrase attachment during comprehension. Journal of Experimental Psychology: Learning, Memory and Cognition, 31, 468-481.

Brooks, P., \& Tomasello, M. (1999). Young children learn to produce passives with nonce verbs. Developmental Psychology, 35, 29-44. 
THE USE OF REPORTED SPEECH IN CHILDREN'S NARRATIVES: A PRIMING STUDY

Cameron, C. A., Hunt, A. K., \& Linton, M. J. (1988). Medium effects on children's story rewriting and story retelling. First Language, 8, 3-18.

Cameron-Faulkner, T., \& Noble, C. (2013). A comparison of book text and Child Directed Speech. First Language, 33, 268-279.

Chang, F., Dell, G., Bock, K., \& Griffin, Z. (2000). Structural priming as implicit learning: A comparison of models of sentence production. Journal of Psycholinguistic Research, 29, 217-29.

Clark, H., \& Gerrig, R. (1990). Quotations as demonstrations. Language, 66, 764-805.

Corley, M., \& Scheepers, C. (2002). Syntactic priming in English sentence production: Categorical and latency evidence from an internet-based study. Psychonomic Bulletin and Review, 9, 126-31.

Dockrell, J. E., Stuart, M., \& King, D. (2010). Supporting early oral language skills for English language learners in inner city preschool provision. British Journal of Educational Psychology, 80, 497-515.

Dunn, L., Dunn, D., Styles, B., \& Sewell, J. (2009). British Picture Vocabulary Scale, 3rd Edition. London, UK: GL Assessment.

Ely, R., \& McCabe, A. (1993). Remembered voices. Journal of Child Language, 20, 671-96. Gamanossi, B., \& Pinto, G. (2014). Theory of mind and language of mind in narratives: Developmental trends from kindergarten to primary school. First Language, 34: 262272

Gámez, P., \& Levine, S. (2012). Oral language skills of Spanish-speaking English language learners: The impact of high-quality native language exposure. Applied Psycholinguistics, 34, 673-696.

Geva, E., \& Olson, D. (1983). Children's story-retelling. First Language, 4, 85-109. 
THE USE OF REPORTED SPEECH IN CHILDREN'S NARRATIVES: A PRIMING STUDY

Goodell, E., \& Sachs, J. (1992). Direct and indirect speech in English-speaking children's retold narratives. Discourse Processes, 15, 395-422.

Goodman, J., Dale, P., \& Li, P. (2008). Does frequency count? Parental input and the acquisition of vocabulary. Journal of Child Language, 35, 515-531.

Hickmann, M. (1993). The boundaries of reported speech in discourse: some developmental aspects. In J. Ludy (Ed.), Reflexive language: Reported speech and metapragmatics (pp. 6390). Cambridge, UK: Cambridge University Press.

Hoff, E. (2006). How social contexts support and shape language development. Developmental Review, 26, 55-88.

Hoff, E., \& Naigles, L. (2002). How children use input to acquire a lexicon. Child Development, 73, 418-433.

Huttenlocher, J., Haight, W., Bryk, A., Seltzer, M., \& Lyons, T. (1991). Early vocabulary growth: Relation to language input and gender. Developmental Psychology, 27, 236-248.

Huttenlocher, J., Vasilyeva, M., Cymerman, E., \& Levine, S. (2002). Language input and child syntax. Cognitive Psychology, 45, 337-374.

Huttenlocher, J., Vasilyeva, M., Waterfall, H., Vevea, J., \& Hedges, L. (2007). Varieties of caregiver speech. Developmental Psychology, 43, 1062-1083.

Huttenlocher, J., Waterfall, H., Vasilyeva, M., Vevea, J., \& Hedges, L. (2010). Sources of variability in children's language growth. Cognitive Psychology, 61, 343-365.

Huttenlocher, J., Vasilyeva, M., \& Shimpi, P. (2004). Syntactic priming in young children. Journal of Memory and Language, 50, 182-195.

Kaschak, M. (2007). Long-term structural priming affects subsequent patterns of language production. Memory \& Cognition, 35, 925-937.

Kaschak, M., Kutta, T., \& Schatschneider, C. (2011). Long-term cumulative structural 
THE USE OF REPORTED SPEECH IN CHILDREN'S NARRATIVES: A PRIMING STUDY

priming persists for (at least) one week. Memory and Cognition, 39, 381-388.

Kidd. E. (2012). Individual differences in syntactic priming in language acquisition. Applied Psycholinguistics, 33, 393-418.

Kirk, S. A., McCarthy, J. J., \& Kirk, W. D. (1968). Illinois Test of Psycholinguistic Abilities. Urbana: University of Illinois Press.

Lonigan, C. J., Anthony, J. L., Bloomfield, B. G., Dyer, S. M., \& Samwel, C. S. (1999). Effects of two shared-reading interventions on emergent literacy skills of at-risk preschoolers. Journal of Early Intervention, 22, 306-322.

MacWhinney, B. (2000). The CHILDES project: Tools for analyzing talk. Mahwah, NJ: Lawrence Erlbaum.

Marulis, L. M., \& Neuman, S. B. (2010). The effects of vocabulary intervention on young children's word learning A meta-analysis. Review of Educational Research, 80, 300-335.

McCabe, A., \& Peterson, C. (1991). Developing narrative structure. Mahwah, NJ: Lawrence Erlbaum.

Messenger, K., Branigan, H., McLean, J., \& Sorace, A. (2008). English-speaking children's early passives: Evidence from syntactic priming. In H. Chan, H. Jacob \& E. Kapia, (Eds.), BUCLD 32: Proceedings of the 32nd annual Boston University conference on language development (pp. 275-286). Somerville, MA: Cascadilla Press.

Messenger, K., Branigan, H., McLean, J., \& Sorace, A. (2009). Semantic factors in young children's comprehension and production of passives. In J. Chandlee, M. Franchini, S. Lord \& G-M. Rheiner, (Eds.), BUCLD 33: Proceedings of the 33rd annual Boston University conference on language development (pp. 355-366). Somerville, MA: Cascadilla Press.

Messenger, K., Branigan, H., \& McLean, J. (2011). Evidence for (shared) abstract 
THE USE OF REPORTED SPEECH IN CHILDREN'S NARRATIVES: A PRIMING STUDY

structure underlying children's short and full passives. Cognition, 121, 268-274.

Mol, S. E., Bus, A. G., de Jong, M. T., \& Smeets, D. J. (2008). Added value of dialogic parent-child book readings: A meta-analysis. Early Education and Development, 19, 7-26.

Mol, S. E., Bus, A. G., \& de Jong, M. T. (2009). Interactive book reading in early education: A tool to stimulate print knowledge as well as oral language. Review of Educational Research, 79, 979-1007.

Morrow, L. B., O’Connor, E. M., \& Smith, J. K. (1990). Effects of a story reading program on the literacy development of at-risk kindergarten children. Journal of Reading Behavior, 22, 255-275.

National Early Literacy Panel. (2008). Developing early literacy: Report of the National Early Literacy Panel. Washington, DC: National Institute for Literacy. Available at http://www.nifl.gov/earlychildhood/NELP/NELPreport.html

Nordqvist, A. (1998). Projecting speech to protagonists in oral and written narratives: A developmental study. Psychology of Language and Communication, 2, 37-46.

Nordqvist, A. (2001). Speech about speech. A developmental study on form and functions of direct and indirect speech. Unpublished doctoral dissertation, University of Goteborg.

O'Neill, D. K., \& Holmes, A. C. (2002). Young preschoolers' ability to reference story characters: the contribution of gestures and character speech. First Language, 22, 73103.

Özyürek, A. (1996). How children talk about a conversation. Journal of Child Language, 23, 693-714.

Phillips, L. M., Norris, S. P., Mason, J. M., \& Kerr, B. M. (1990). Effects of early literacy intervention on kindergarten achievement. National Reading Conference Yearbook, 39 , 199-207. 
THE USE OF REPORTED SPEECH IN CHILDREN'S NARRATIVES: A PRIMING STUDY

Pickering, M., \& Ferreira, V. (2008). Structural priming: A critical review. Psychological Bulletin, 134, 427-459.

Pickering, M., \& Branigan, H. (1998). The representation of verbs: Evidence from syntactic priming in language production. Journal of Memory and Language, 39, 633-651.

Rowland, C. , Chang, F., Ambridge, B., Pine, J., \& Lieven, E. (2012). The development of abstract syntax: Evidence from structural priming and the lexical boost. Cognition, 125, 49-63.

Savage, C., Lieven, E., Theakston, A., \& Tomasello, M. (2003). Testing the abstractness of children's linguistic representations: Lexical and structural priming of syntactic constructions in young children. Developmental Science, 6, 557-567.

Savage, C., Lieven, E., Theakston, A., \& Tomasello, M. (2006). Structural priming as implicit learning in language acquisition: The persistence of lexical and structural priming in 4-year-olds. Language Learning and Development, 2, 27-49.

Schickedanz, J. A., \& McGee, L. M. (2010). The NELP Report on Shared Story Reading Interventions (Chapter 4) Extending the Story. Educational Researcher, 39, 323-329.

Semel, E., Wiig, E., \& Secord, W. (2006). Clinical evaluation of language fundamentals $®$ $4^{\text {th }}$ edition (CELF® - 4). Oxford, UK: Pearson Assessment.

Shimpi, P., Gámez, P., Huttenlocher, J., and Vasilyeva, M. (2007). Syntactic priming in 3- and 4-year-old children: Evidence for abstract representations of transitive and dative forms. Developmental Psychology, 43, 1334-46.

Skarabela, B., \& Serratrice, L. (2009). 'The doctor's mother' or 'the mother of the doctor'?: Syntactic priming of possessive noun phrases in English preschoolers Online Supplement of the Proceedings of the Boston University Conference on Language Development. 
THE USE OF REPORTED SPEECH IN CHILDREN'S NARRATIVES: A PRIMING STUDY

Talley, S., Lancy, D. F., \& Lee, T. R. (1997). Children, storybooks, andcomputers. Reading Horizons, 38, 117-128.

Thothathiri, M., \& Snedeker, J. (2008). Give and take: Syntactic priming during spoken language comprehension. Cognition, 51, 51-56.

Tomasello, M., Brooks, P. J., \& Stern, E. (1998). Learning to produce passive utterances through discourse. First Language, 18, 223-237.

Vasilyeva, M., Huttenlocher, J., \& Waterfall, H. (2006). Effects of language intervention on syntactic skill levels in preschoolers. Developmental Psychology, 42, 164-174.

Wade, E., \& Clark, H. H. (1993). Reproduction and demonstration in quotations. Journal of Memory and Language, 32, 805-819.

Weizman, Z., \& Snow, C. (2001). Lexical output as related to children's vocabulary acquisition: Effects of sophisticated exposure and support for meaning. Developmental Psychology, 37, 265-279.

Zevenbergen, A. A., Whitehurst, G. J., \& Zevenbergen, J. A. (2003). Effects of a sharedreading intervention on the inclusion of evaluative devices in narratives of children from low-income families. Journal of Applied Developmental Psychology, 24, 1-15. 